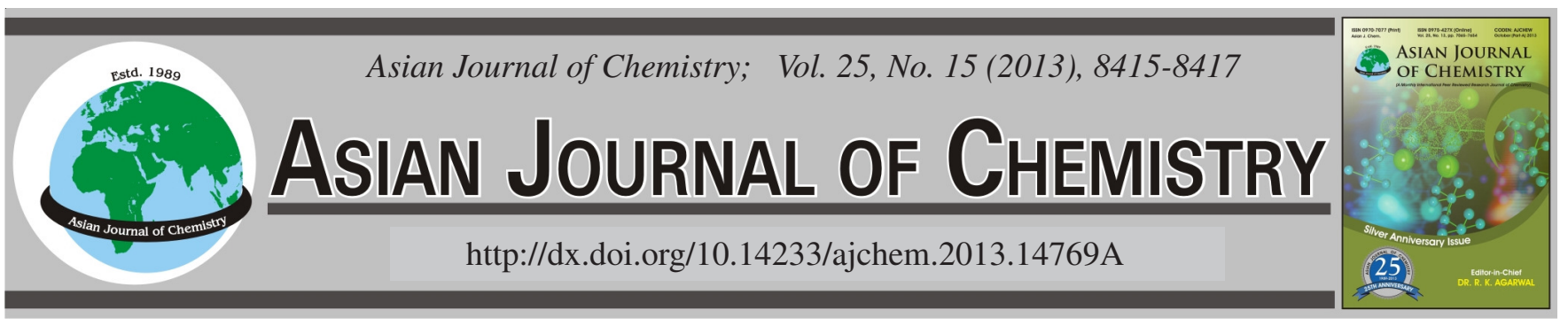

\title{
Copper(II) Complex of 2-Hydroxy-4-oxyacetate-benzoic Acid: Synthesis, Structure and Photoluminescence
}

\author{
Wei-Ji Hu ${ }^{1}$, XIAO-Ju Chen $^{2}$, Yi QIN ${ }^{1}$ and Guo-Liang Zhao ${ }^{1,2, *}$
}

${ }^{1}$ Xingzhi College, Zhejiang Normal University, Jinhua 321004, P.R. China

${ }^{2}$ College of Chemistry and Life Science, Zhejiang Normal University, Jinhua 321004, P.R. China

*Corresponding author: Fax: +86 579 82282269; Tel: +86 579 82282061; E-mail: sky53@zjnu.cn

(Received: 3 November 2012;

Accepted: 23 August 2013)

AJC-13964

\begin{abstract}
A novel copper(II) complex (1) $\mathrm{Cu}(\mathrm{L}) \cdot(\text { phen })_{2} \cdot 10 \mathrm{H}_{2} \mathrm{O}$ was synthesized from 2- hydroxy-4-oxyacetate-benzoic acid (HL), phenanthroline (phen) and $\mathrm{Cu}\left(\mathrm{NO}_{3}\right)_{2} \cdot 2.5 \mathrm{H}_{2} \mathrm{O}$ and characterized by elemental analysis, IR and X-ray crystallographically. The single-crystal X-ray diffraction studies demonstrated that complex is crystallize in triclinic system, space group $\mathrm{P}_{1}$, with $\mathrm{a}=0.9177(6) \mathrm{nm}, \mathrm{b}=1.5123(5) \mathrm{nm}, \mathrm{c}=$ $1.5753(3) \mathrm{nm}, \alpha=62.263^{\circ}, \beta=77.639^{\circ}, \gamma=80.098^{\circ}, \mathrm{V}=1.883(7) \mathrm{nm}^{3}, \mathrm{Z}=2, \mathrm{M}_{\mathrm{r}}=814.25, \mathrm{~F}_{(000)}=850.0, \mathrm{D}_{\mathrm{c}}=1.436 \mathrm{~g} \cdot \mathrm{cm}-3, \mu\left(\mathrm{M}_{0} \mathrm{~K}_{\alpha}\right)$ $=0.675 \mathrm{~mm}^{-1}$. It turned out that four $\mathrm{N}$ atoms and one carboxyl $\mathrm{O}$ atom coordinate to $\mathrm{Cu}$ (II), forming a five-coordination trigonal bipyramid geometry. The complex is luminescent in the solid state, which indicate that it may be an excellent candidate for potential photoactive material. CCDC: 883096.
\end{abstract}

Key Words: Copper compound, 2-Hydroxy-4-oxyacetate-benzoic acid, Crystal structure, Luminescent.

\section{INTRODUCTION}

The design and synthesis of metal-organic compound have undergone rapid development because of their particular topologies ${ }^{1}$ and beneficial properties in gas adsorption, separation $^{2}$, catalysis $^{3}$, magnetism $^{4}$, photochemistry $^{5,6}$. For having potential applications as sensors ${ }^{7}$, highly selective guest inclusion $^{8}$ and delivery of specific chemicals ${ }^{9}$. Modification of the size and shape of the ligands often leads to a change in the structures and properties of the resulting compound. The selection of organic ligands plays a crucial role in the rational design and construction of coordination polymers, thus we successfully designed a new multicarboxylate ligand 2-hydroxy4-oxyacetate-benzoic acid (HL) based on the following considerations: (1) the rigidity of the benzene ring and flexibility of substituent groups can provide diversiform coordination modes; (2) further flexible carboxyl groups are feasible to link discrete clusters to give an extended network containing high connected nodes; (3) there are many $\mathrm{O}$ atoms can act as hydrogen bonding acceptors, it's easy to assemble supramolecular network ${ }^{10}$. Therefore, much work is still necessary to understand the coordination chemistry of this ligand. As far as we know, the complex constructed by 2-hydroxy-4-oxyacetatebenzoic acid ligand has never been reported, this prompted us to exploring the coordination chemistry of 2-hydroxy-4-oxyacetate benzoic acid ligand and creating new materials with excellent properties. In this paper, we report a novel luminescent complex 1 based on the assembly of 2-hydroxy-4oxyacetate-benzoic acid (HL) and phenanthroline with copper metal under hydrothermal conditions and fully characterized by infrared spectroscopy, elemental analysis, thermogravimetric analysis and X-ray crystallographically it's worth noting that the complex may be an excellent candidate for potential photoactive material.

\section{EXPERIMENTAL}

All reagents and solvents used were of commercially available quality and without purified before using. FTIR spectra were recorded on a Nicolet NEXUS 670 FTIR spectrophotometer using $\mathrm{KBr}$ discs in the range of $4000-400 \mathrm{~cm}^{-1}$. Elemental analysis was performed on $\mathrm{C}, \mathrm{H}, \mathrm{N}$ elemental analyzer, Elementar Vario EL III. A Mettler Toledo thermal analyzer TGA/SDTA $851^{\mathrm{e}}$ was used to carry out the thermoanalytical analysis with a heating rate of $10^{\circ} \mathrm{C} \mathrm{min}^{-1}$ from $30-800^{\circ} \mathrm{C}$ in air atomsphere. Fluorescent spectrum were recorded at room temperature on an Edinburgh FL920 phosphorimeter.

Synthesis of the compound: A mixture of 2-hydroxy-4oxyacetate-benzoic acid $(0.5 \mathrm{mmol}, 0.135 \mathrm{~g}), \mathrm{Cu}\left(\mathrm{NO}_{3}\right)_{2} \cdot 2.5 \mathrm{H}_{2} \mathrm{O}$ (0.5 mmol, $0.114 \mathrm{~g})$, phenanthroline (0.2 mmol, $0.036 \mathrm{~g})$, $\mathrm{NaOH}$ (1.0 mmol, $0.0403 \mathrm{~g})$ and $\mathrm{H}_{2} \mathrm{O} /$ ethanol $(15 \mathrm{~mL})$ was placed in a $25 \mathrm{~mL}$ autoclave and heated at $100{ }^{\circ} \mathrm{C}$ for 7 days 
and then cooled to room temperature at the speed of $1.5^{\circ} \mathrm{C} / \mathrm{h}$. The blue block crystals were obtained. Washed with water and ethanol, then dried in air (37\% yield, based on phen). Anal. calcd. (\%) for $\mathrm{C}_{33} \mathrm{H}_{42} \mathrm{~N}_{4} \mathrm{O}_{16} \mathrm{Cu}: \mathrm{C}, 48.58 ; \mathrm{H}, 5.18 ; \mathrm{N} 6.84$. Found (\%): C, 48.67; H, 5.20; N, 6.88. IR (KBr, $\left.v_{\max }, \mathrm{cm}^{-1}\right)$ : 3414 (s), 3060 (w), 2970 (w), 1701(m), 1686(m), 1609(s), 1518(s), 1427(s), 1341(w), 1253 (w), 1181(m), 1107(m), 1052(s), 852(m), 724(s).

X-Ray crystallography: A single crystal of the compound with dimentions of $0.347 \mathrm{~mm} \times 0.154 \mathrm{~mm} \times 0.088 \mathrm{~mm}$ was selected and mounted on a glass fiber and collected diffraction data on a Bruker Smart APEX II CCD diffractometer with graphite monochromated $\mathrm{M}_{0} \mathrm{~K}_{\alpha}$ radiation $(\lambda=0.071073 \mathrm{~nm})$ at 296(2) K. Structure was solved by direct methods using SHELXS-9 $7^{11}$ and refined on the $\mathrm{F}^{2}$ by full-matrix least-square method with SHELXL-97 ${ }^{12}$. All non-hydrogen atoms were refined anisotropically. Hydrogen atoms were placed in geometrically calculated positions and refined by using a riding mode. Experimental details for X-ray data collection are presented in Table-1 and the selected bond lengths and angles are listed in Table-2. CCDC No. 883096 of 1 contains the supplementary crystallographic data for this paper. These data can be obtained free of charge from the Cambridge Crystallographic Data Centre.

\section{RESULTS AND DISCUSSION}

The IR spectra of complex 1 exhibit broad strong absorptions at $3414 \mathrm{~cm}^{-2}$, which corresponds to the existence of hydrogen bonds formed by water molecules, as well as the asymmetric stretching vibrations of hydroxyl groups in the complex. Weak absorptions observed at $2970 \mathrm{~cm}^{-1}$ can be ascribed to the $v\left(\mathrm{CH}_{2}\right)$ of the HL ligand. The characteristic band is shown at $1609 \mathrm{~cm}^{-1}$ may be assigned to the asymmetric stretching vibration of the carboxylate groups, While symmetric stretching the feature $1427 \mathrm{~cm}^{-1}$ is associated with the symmetric $\left(\mathrm{COO}^{-}\right)$stretching vibrations. The $\Delta \mathrm{v}\left(\mathrm{v}_{\mathrm{as}}\left(\mathrm{COO}^{-}\right)-\mathrm{v}_{\mathrm{s}}(\mathrm{COO}-)\right)$ values are $182 \mathrm{~cm}^{-1}$ (more than $160 \mathrm{~cm}^{-1}$ ), indicating the coordination of $\mathrm{L}^{-}$with $\mathrm{Cu}(\mathrm{II})$ in monodentate modes ${ }^{13}$, which is well consistent with the X-ray diffraction structural analysis.

Structural description: The crystal structure of the complex $1 \mathrm{Cu}(\mathrm{L}) \cdot(\text { phen })_{2} \cdot 10 \mathrm{H}_{2} \mathrm{O}$ is shown in Fig. 1. Its asymmetric unit consists of one $\mathrm{Cu}(\mathrm{II})$, one $\mathrm{L}^{-}$, two phenanthroline and 10 free water molecules. $\mathrm{Cu}$ (II) atom is coordinated by one flexible carboxyl groups from $\mathrm{L}^{-}(\mathrm{Cu}-\mathrm{O}(2) 0.1980(3) \mathrm{nm})$ and four $\mathrm{N}$ donor from two symmetrical independent phen ligand (Cu-N 0.1990(3) to $0.2143(3) \mathrm{nm})$ to furnish a trigonal bipyramid geometry, the selected coordination bond lengths and angles for $\mathbf{1}$ are listed in the Table-2. In the coordination environment of $\mathrm{Cu}(\mathrm{II})$ (Fig. 2), the $\mathrm{O}(2), \mathrm{N}(1)$ and $\mathrm{N}(3)$ define a trigonal plane, whereas the other two $\mathrm{N}$ atoms occupies the axial positions from the opposite direction.

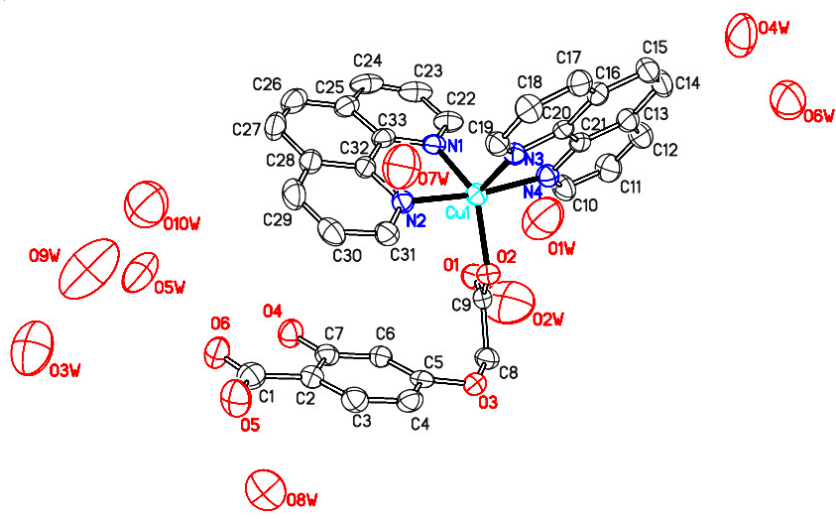

Fig. 1. Thermal eclipse diagram of the nonsymmetrical unit of $\mathbf{1}$ with ellipsoids at $30 \%$ probability. The hydrogen atoms are omitted

\begin{tabular}{|c|c|c|c|}
\hline \multicolumn{4}{|c|}{$\begin{array}{c}\text { TABLE-1 } \\
\text { CRYSTALLOGRAPHIC DATA FOR THE COMPLEX }\end{array}$} \\
\hline Empirical formula & $\mathrm{C}_{33} \mathrm{H}_{42} \mathrm{CuN}_{4} \mathrm{O}_{16}$ & Calculated density $\left(\mathrm{Mg} / \mathrm{m}^{3}\right)$ & 1.436 \\
\hline Formula weight & 814.25 & Absorption coefficient $\left(\mathrm{mm}^{-1}\right)$ & 0.657 \\
\hline Temperature (K) & 296(2) & $\mathrm{F}_{(000)}$ & 850.0 \\
\hline Wavelength (nm) & 0.071073 & Crystal size (mm) & $0.347 \times 0.154 \times 0.088$ \\
\hline Crystal system & Triclinic & $\theta$ range for data collection $\left({ }^{\circ}\right)$ & 1.48 to 27.53 \\
\hline Space group & $\mathrm{P}_{1}$ & Limiting indices & $-11 \Leftarrow \mathrm{h} \Leftarrow 11,-16 \Leftarrow \mathrm{k} \Leftarrow 19,-20 \Leftarrow 1 \Leftarrow 20$ \\
\hline $\mathrm{a}(\mathrm{nm})$ & $0.9117(6)$ & Reflections collected / unique & $28406 / 8468\left[\mathrm{R}_{\text {(int) }}=0.0426\right]$ \\
\hline $\mathrm{b}(\mathrm{nm})$ & $1.5123(5)$ & Refinement method & Full-matrix least-squares on $\mathrm{F}^{2}$ \\
\hline $\mathrm{c}(\mathrm{nm})$ & $1.5753(3)$ & Data/restraints/parameters & $8468 / 0 / 487$ \\
\hline$\alpha\left({ }^{\circ}\right)$ & $62.263(3)$ & Goodness-of-fit (on $\mathrm{F}^{2}$ ) & 0.990 \\
\hline$\beta\left({ }^{\circ}\right)$ & $77.639(3)$ & Final $R$ indices $[\mathrm{I}>2 \sigma(\mathrm{I})]$ & $\mathrm{R}_{1}=0.0644, \mathrm{wR}_{2}=0.1541$ \\
\hline$\gamma\left(\left(^{\circ}\right)\right.$ & $80.098(3)$ & $\mathrm{R}$ indices (all data) & $\mathrm{R}_{1}=0.1560, \mathrm{wR}_{2}=0.1931$ \\
\hline Volume $\left(\mathrm{nm}^{3}\right)$ & $1.88374(2)$ & 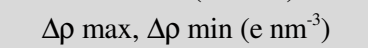 & 596 and -395 \\
\hline $\mathrm{Z}$ & 2 & - & - \\
\hline
\end{tabular}

\begin{tabular}{cccccc}
\multicolumn{7}{c}{ TABLE -2 } \\
\hline Bond & Length & SELECTED BOND LENGTHS (nm) AND ANGLES ( $\left(^{\circ}\right)$ & Bond & Length \\
\hline $\mathrm{Cu}(1)-\mathrm{O}(2)$ & $0.1980(3)$ & $\mathrm{Cu}(1)-\mathrm{N}(4)$ & $0.1998(3)$ & $\mathrm{Cu}(1)-\mathrm{N}(3)$ & $0.2143(3)$ \\
$\mathrm{Cu}(1)-\mathrm{N}(2)$ & $0.1990(3)$ & $\mathrm{Cu}(1)-\mathrm{N}(1)$ & $0.2080(3)$ & - & - \\
\hline Angle & $\left({ }^{\circ}\right)$ & $\mathrm{Angle}$ & $\left({ }^{\circ}\right)$ & $\mathrm{Angle}$ & $\left({ }^{\circ}\right)$ \\
\hline $\mathrm{O}(2)-\mathrm{Cu}(1)-\mathrm{N}(2)$ & $91.29(12)$ & $\mathrm{N}(2)-\mathrm{Cu}(1)-\mathrm{N}(1)$ & $81.56(13)$ & $\mathrm{N}(4)-\mathrm{Cu}(1)-\mathrm{N}(3)$ & $79.98(13)$ \\
$\mathrm{O}(2)-\mathrm{Cu}(1)-\mathrm{N}(4)$ & $96.87(12)$ & $\mathrm{N}(4)-\mathrm{Cu}(1)-\mathrm{N}(1)$ & $94.71(13)$ & $\mathrm{N}(1)-\mathrm{Cu}(1)-\mathrm{N}(3)$ & $114.79(11)$ \\
$\mathrm{N}(2)-\mathrm{Cu}(1)-\mathrm{N}(4)$ & $171.27(13)$ & $\mathrm{O}(2)-\mathrm{Cu}(1)-\mathrm{N}(3)$ & $109.99(11)$ & - & - \\
$\mathrm{O}(2)-\mathrm{Cu}(1)-\mathrm{N}(1)$ & $135.02(12)$ & $\mathrm{N}(2)-\mathrm{Cu}(1)-\mathrm{N}(3)$ & $94.36(12)$ & - & - \\
\hline
\end{tabular}




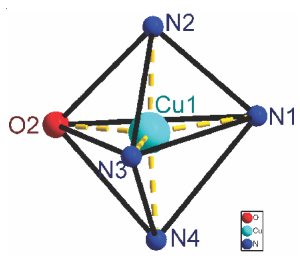

Fig. 2. Coordination polyhedron of $\mathrm{Cu}(\mathrm{II})$ in complex $\mathbf{1}$

In addition, there exists strong intermolecular $\mathrm{O}-\mathrm{H} \cdots \mathrm{O}$ hydrogen bonding interactions between vast free water molecules and uncoordinated oxygen atom of $\mathrm{L}^{-}$as listed in Table-3. Meanwhile, there are infinite parallel aromatic rings from the $\mathrm{L}^{-}$and phen. Thus, a 3D supramolecular network has been generated by the hydrogen bonding and $\pi-\pi$ stacking interactions (Fig. 3).

\begin{tabular}{|c|c|c|c|c|}
\hline \multicolumn{5}{|c|}{ TABLF } \\
\hline D-H $\cdots A$ & D-H & $\mathrm{H} \cdots \mathrm{A}$ & $\mathrm{D} \cdots \mathrm{A}$ & D-H $\cdots A$ \\
\hline $\mathrm{O}(8 \mathrm{~W}$ & 85 & 9 & 2836 & 173 \\
\hline & & & & \\
\hline & 0.085 & 24 & 6) & 21.1 \\
\hline & 8 & 3 & & \\
\hline & 5 & & & \\
\hline & 35 & 0 & & \\
\hline & 85 & & & 169.2 \\
\hline & 0.085 & 0.187 & 0.2 & 169.2 \\
\hline & 0.085 & 0.252 & $0.2819(12)$ & 101.9 \\
\hline $\mathrm{O}(9 \mathrm{~W})-\mathrm{H}$ & 0.085 & 0.181 & $0.2595(11)$ & 152.4 \\
\hline $\mathrm{O}(3 \mathrm{~W})-\mathrm{H}(3 \mathrm{WA}) \cdots \mathrm{O}(5$ & 0.085 & 0.285 & $0.3029(8)$ & 93.6 \\
\hline & 0.085 & 0.240 & $0.2770(7)$ & 107.2 \\
\hline & 0.0 & & & \\
\hline & 0.0 & & & 13 \\
\hline & & & & \\
\hline & 0.085 & 0.202 & $0.2857(7)$ & 166.9 \\
\hline $\mathrm{O}(4)-\mathrm{H}(20 \mathrm{~A}) \cdots \mathrm{O}(6)$ & 0.082 & 0.179 & $0.2515(4)$ & 147.0 \\
\hline
\end{tabular}

Symmetry codes: ${ }^{\# 1}-\mathrm{x}+1,-\mathrm{y}+1,-\mathrm{z}+1 ;{ }^{\text {\#2 }} \mathrm{x}+1, \mathrm{y}, \mathrm{z} ;{ }^{\text {\#3 }}-\mathrm{x}+2,-\mathrm{y}+1,-\mathrm{z}+1$; ${ }^{\# 4} \mathrm{x}+1, \mathrm{y}+1, \mathrm{z} ;{ }^{\# 5}-\mathrm{x}+1,-\mathrm{y}+1,-\mathrm{z}+2 ;{ }^{\# 6} \mathrm{x}, \mathrm{y}-1, \mathrm{z} ;{ }^{\# 7} \mathrm{x}-1, \mathrm{y}-1, \mathrm{z} ;{ }^{\# 8}-\mathrm{x}+2,-\mathrm{y}+1,-\mathrm{z}+2$; ${ }^{\#}-\mathrm{x}+2,-\mathrm{y}+2,-\mathrm{z}+2$.

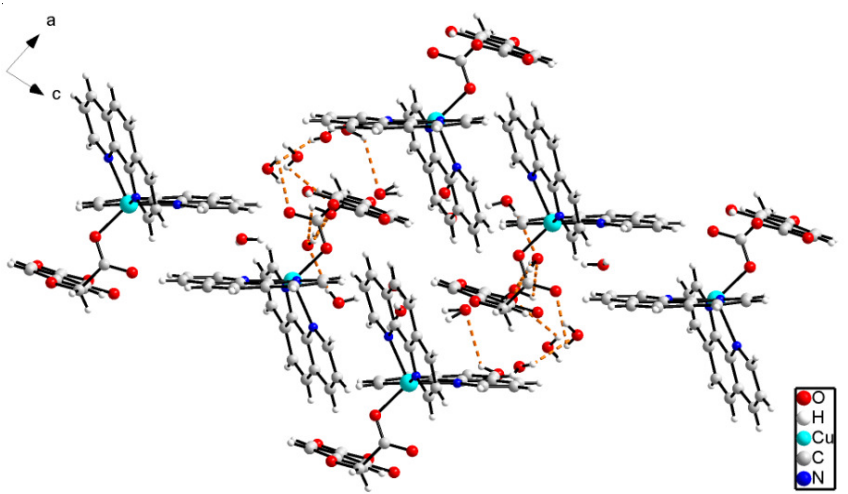

Fig. 3. Packing plot of complex $\mathbf{1}$

Fluorescent property: Considering the formed $\mathrm{Cu}(\mathrm{II})$ center is inclined to transfer an electron to the chromophore after deprotonation ${ }^{14}$. The solid luminescent of complex $\mathbf{1}$ and HL ligand were investigated at room temperature. As depicted in Fig. 4, complex 1 exhibit fluorescent emission with the maxima at $501 \mathrm{~nm}\left(\lambda_{\mathrm{ex}}=346 \mathrm{~nm}\right)$. Such fluorescence behaviour may be attributed to the intraligand transition of coordinated ligand. Since similar emission at $420 \mathrm{~nm}\left(\lambda_{\mathrm{ex}}=325 \mathrm{~nm}\right)$ was observed for the free HL ligand. The red-shifted fluorescence spectra of $\mathbf{1}$ was attributed to both the deprotonated effect of $\mathrm{HL}$ and the coordination interactions of the organic ligands to $\mathrm{Cu}(\mathrm{II})$, in this case, the $\mathrm{Cu}(\mathrm{II})$ complex will take part in the $\pi$ system ${ }^{15}$, effectively increasing the conformational rigidity and asymmetry of the ligand and reduces the loss of energy by nonradiative decay of the intraligand $\left(\pi-\pi^{*}\right)$ excited state.

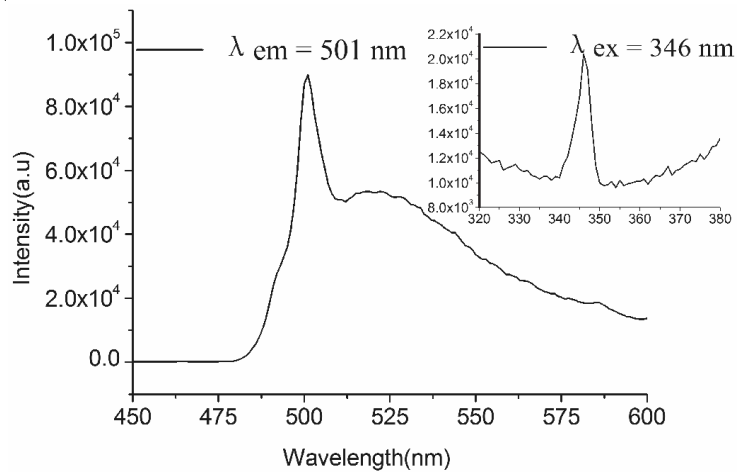

(a)

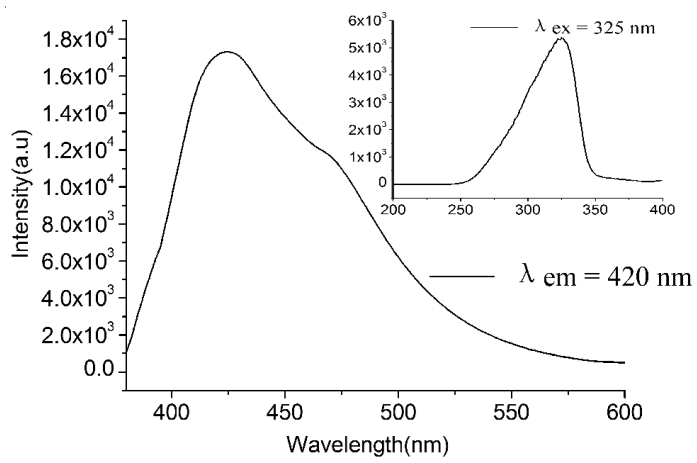

(b)

Fig. 4. Excitation and emission spectra in the solid state at room temperature: (a) complex 1 (b) HL ligand

\section{REFERENCES}

1. O.M. Yaghi, M. O'Keeffe, N.W. Ockwig, H.K. Chae, M. Eddaoudi and J. Kim, Nature, 423, 705 (2003).

2. Y. Gurdal and S. Keskin, Ind. Eng. Chem. Res., 51, 7373 (2012).

3. A.M. Shultz, O.K. Farha, J.T. Hupp and S.T. Nguyen, J. Am. Chem. Soc., 131, 4204 (2009).

4. Y.N. Guo, G.F. Xu, P. Gamez, L. Zhao, S.Y. Lin, R. Deng, J. Tang and H.J. Zhang, J. Am. Chem. Soc., 132, 8538 (2010).

5. K. Binnemans, Chem. Rev., 109, 4283 (2009).

6. J.W. Steed, Chem. Soc. Rev., 38, 506 (2009).

7. B.L. Chen, L.B. Wang, F. Zapata, G. Qian and E.B. Lobkovsky, J. Am. Chem. Soc., 130, 6718 (2008)

8. L. Hou, Y.Y. Lin and X.M. Chen, Inorg. Chem., 47, 1346 (2008).

9. P. Horcajada, C. Serre, G. Mauri, N.A. Ramsahye, F. Balas, M. ValletRegí, M. Sebban, F. Taulelle and G. Férey, J. Am. Chem. Soc., 130, 6774 (2008).

10. C.Q. Wan, G.S. Li, X.D. Chen and T.C. W. Mak, Cryst. Growth Des., 8, 3897 (2008).

11. G.M. Sheldrick, SHELXS-97. Program for the Solution of Crystal Structures. University of Götingen, Germany (1997).

12. G.M. Sheldrick, SHELXL-97. Program for the Refinement of Crystal Structures. University of Götingen, Germany (1997).

13. K. Nakamoto, Translated by D.R. Huang and R.Q. Wang, Infrared and Raman Spectra of Inorganic and Coordination Compounds, edn. 3, Beijing: Chemical Industrial Press, pp. 233, 236 (1986).

14. L. Fabbrizzi, M. Lichelli, P. Pallavicini, A. Perotti and D. Sacchi, Angew. Chem. Int. Ed., 33, 1975 (1994).

15. Z.C. Xu, X.H. Qian and J.N. Cui, Org. Lett., 7, 3029 (2005). 